\title{
Rethinking the distribution of English finite clausal complements
}

\section{Evidence from complementiser-how clauses*}

\author{
Rachel Nye \\ Ghent University
}

\begin{abstract}
This paper advocates a new conception of the properties which determine the distribution of finite clausal complements (FCCs) in English. I argue against the orthodox view that FCCs are selected by matrix predicates on the basis of their interpretive type (Grimshaw 1979; Rizzi 1997; Ginzburg \& Sag 2000), and propose that distribution rather depends on the specification of the FCC in terms of the syntactically encoded properties $[+/-w h,+/$-factive]. This proposal is motivated by new distributional patterns which emerge when the typology of English FCCs is expanded to take into account complementiser-how clauses (CHCs) (Legate 2010; Nye 2012). CHCs have their own unique interpretation, yet, strikingly, have exactly the same distribution as embedded exclamatives. This is unexpected under the traditional view of FCC selection, but is explained if $\mathrm{CHCs}$ and exclamatives are selected on the basis of a common $[+w h,+$ factive $]$ syntactic specification.
\end{abstract}

Keywords: clausal complementation, interpretive type, English, factivity, wh.

\section{The traditional view of finite clausal complement distribution}

Grimshaw (1979:285) proposes that finite clausal complements (FCCs) belong to one of three different interpretive types, which are motivated on the basis of "systematic differences in semantics": propositions, questions and exclamations. ${ }^{1}$ She further claims that the distribution of FCCs is dependent on their interpretive type - matrix predicates specify which interpretive types they select for. ${ }^{2}$ Thus whilst forget in (1) is compatible with complements belonging to any of the three interpretive types, think can only be combined with FCCs of type 'proposition' (2), ask only with FCCs of type 'question' (3). ${ }^{3}$ Table 1 summarises these distributional 
regularities, and gives additional examples of predicates which place the same selectional requirements on their clausal complements.

(1) a. John forgot [that Mary lived in Spain].

[proposition]

b. John forgot [where Mary lived].

[question]

c. John forgot [what a lot of time Mary had spent in Spain]. [exclamation]

(2) a. John thought [that Mary lived in Spain].

[proposition]

b. ${ }^{\star}$ John thought [where Mary lived].

$\left[{ }^{*}\right.$ question]

c. ${ }^{\star}$ John thought [what a lot of time Mary had spent in Spain].[ ${ }^{*}$ exclamation]

(3) a. ${ }^{*}$ John asked [that Mary lived in Spain].

[*proposition]

b. John asked [where Mary lived].

[question]

c. ${ }^{\star}$ John asked [what a lot of time Mary had spent in Spain]. [*exclamation]

For Grimshaw (1979), selection is purely semantic, and the syntactic structure of a clause is relevant only in so far as it provides the input to rules which assign an interpretive type to a clause. However, she recognises that "treating complement selection syntactically is possible... if the relevant aspects of semantic interpretation are built into syntactic structure" (Grimshaw 1979:317). This is precisely what we see in Rizzi's (1997:362) cartographic account, where "[c]omplementizers express the fact that a sentence is a question, a declarative, an exclamative... and can be selected as such by a higher selector". Nevertheless, this still adheres to the same basic idea that FCCs are selected by matrix predicates on the basis of their interpretive type, and that the empirical patterns to be accounted for are as presented in Table 1 . The only difference is that interpretive type has a direct syntactic correlate.

Table 1. Summary of the types of FCC selected by different predicates (Grimshaw 1979)

\begin{tabular}{lllll}
\hline & & proposition & question & exclamation \\
\hline (1) $\quad$ forget (learn, see) & $\sqrt{ }$ & $\sqrt{ }$ & $\sqrt{ }$ \\
(2) $\quad$ think (believe, claim) & $\sqrt{ }$ & $*$ & $*$ \\
(3) $\quad$ ask (wonder) & $*$ & $\sqrt{ }$ & $*$ \\
\hline
\end{tabular}

In this paper, I show that approaches which posit that FCCs are selected by matrix predicates on the basis of their interpretive type cannot parsimoniously account for the range of distributional data presented here. To make the argument concrete, I use accounts in the spirit of Grimshaw (1979), where interpretive type is construed as purely semantic, to illustrate this point. However, Rizzi (1997) and other accounts which posit FCC-selection on the basis of syntactically-encoded interpretive type have the same shortcomings. Note that the goal of this paper is to provide a more accurate characterisation of the properties which are relevant to the distribution of FCCs than has been offered to date. Like these earlier accounts, 
it does not tackle the deeper question of why predicates differ in the selectional requirements they place on their complements.

\section{Expanding the inventory of finite clausal complements: complementiser-how clauses}

Since Kiparsky \& Kiparsky (1971), two types of that-clause complement have been distinguished: factive (4) and non-factive (5). I follow these authors in using the term 'factive' to characterise the presupposition "that the complement of the sentence expresses a true proposition" (Kiparsky \& Kiparsky 1971:345). Whilst for Kiparsky \& Kiparsky (1971:345) it is speakers who presuppose, like Karttunen (1973) I consider presupposition rather to be a property of sentences. The relevant definition which I make use of is that of Shanon (1976:247) for whom "[a] sentence $S$ logically presupposes a sentence $P$ just in case $S$ logically implies $P$, and the negation of $S$ also logically implies $P$ ". Thus, the that-clause complements to the predicate forget (4) are factive, whilst the that-clause complements to the predicate think are non-factive (5).

(4) a. John forgot [that Mary was never late].

$\Rightarrow$ Mary was never late

b. John didn't forget [that Mary was never late]. $\Rightarrow$ Mary was never late

(5) a. John thought [that Mary was never late].

$\nRightarrow$ Mary was never late

b. John didn't think [that Mary was never late]. $\nRightarrow$ Mary was never late

On the basis of this semantic distinction, Ginzburg \& Sag (2000:72-78) consider that-clauses to belong to two distinct interpretive types. Non-factive that-clauses qualify as propositions, just as in Grimshaw (1979). Factive that-clauses are assigned the interpretive type 'fact'. Predicates differ in which types they permit as complements. The picture presented in the two accounts is summarised in Table 2.

Table 2. Summary of the types of that-clause complement selected by different predicates

\begin{tabular}{llll}
\hline & Grimshaw (1979) & \multicolumn{2}{l}{ Ginzburg \& Sag (2000) } \\
\cline { 2 - 4 } & proposition & proposition & fact \\
\hline forget (know, remember) & $\sqrt{ }$ & $*$ & $\sqrt{ }$ \\
think (believe, claim) & $\sqrt{ }$ & $\sqrt{ }$ & $*$ \\
ask (wonder) & $*$ & $*$ & $*$ \\
\hline
\end{tabular}

Complementiser-how clauses (CHCs) such as (6) and (7) are another kind of factive complement. Example (8) is parallel to (4) above, but involves a $\mathrm{CHC}$ instead of a that-clause under forget. Examples parallel to (5) cannot be constructed, as $\mathrm{CHCs}$, like other wh-clauses, are disallowed under think, as under almost all 
predicates which permit non-factive that-clause complements. ${ }^{4}$ Thus whilst thatclause complements come in two flavours, factive and non-factive, CHCs appear always to be factive. ${ }^{5}$

(6) Jurors have heard [how the boy had been placed on the child protection register with Haringey social services nine months before his death].

(From The Guardian, 31 October, 2008, p. 8 col.5)

(7) She told me [how she hadn't seen her husband for 3 months] and wouldn't see him for yet another 3 months. ${ }^{6} \quad$ (From http://www.chronofhorse.com/ forum/archive/index.php/t-218829.html. Last accessed on 16 June, 2013)

(8) a. ohn forgot [how Mary was never late]. $\quad \Rightarrow$ Mary was never late

b. She didn't forget [how Mary was never late]. $\Rightarrow$ Mary was never late

Despite having received some attention in the recent literature (Legate 2010; Nye 2012), CHCs remain under-studied in comparison to other English FCCs. Examples such as (9) and (10) make clear, however, that CHCs are not simply equivalent in interpretation to factive that-clauses, but contribute something additional. Warner (1982:182) notes that in (9b) in comparison to (9a) "some further content to Paul's statement is suggested, and the speaker merely reports the gist of it". This seems to relate to what Defrancq (2009) characterises as the 'narrative' function of CHCs. This is even more apparent in the attested CHC in (10), which does not simply present the factual recollection of a situation, but also appears to reactivate or elaborate on particular details of this. With a that-clause, the result is at best stylistically odd, despite the fact that the combination remember + thatclause is in principle grammatical. Whilst this is only a first approximation of the interpretive distinction between $\mathrm{CHCs}$ and factive that-clauses, which remains to be refined and formalised in future work, the crucial point is that $\mathrm{CHCs}$ do differ in interpretation from factive that-clauses.

(9) a. Paul told me [that he was in love with Mary].

b. Paul told me [how he was in love with Mary].

[Warner (1982: 182), ex. (22), (23)]

(10) And then there was Autumn. Her golden hair was like the crisp leaves under a tree on a cool fall morning. Every morning he remembered [how/\#that she would sit under the maple tree in the school lawn and hold the sketchbook in her hands]. Her satchel was always on the ground, open, and full of pastels and pencils. http://www.buzzle.com/articles/being-a-man-likesaint-chapter-ten.html (22 February, 2012)

It is by no means a new observation that (embedded) exclamatives are also factive (Grimshaw 1979; Zanuttini \& Portner 2003). They show the same semantic 
behaviour as other factive complement clauses, as (11) illustrates. Nevertheless, it is even clearer than it was in the case of CHCs that factivity alone does not suffice to characterise the interpretation of exclamatives. As Grimshaw (1979:284) notes, "the value of $w h$ must be in some sense extreme". Thus although CHCs and embedded exclamatives may be string-identical (12), we can establish that we are nevertheless dealing with two different types of wh-clause from the fact that two distinct readings are possible, as indicated in (i) and (ii). ${ }^{7}$

(11) a. She forgot [what a great cook he was]. $\quad \Rightarrow$ he was a great cook b. She didn't forget [what a great cook he was]. $\Rightarrow$ he was a great cook

(12) He told me [how she had longed to go home].

(i) $\approx$ He told me that she had longed to go home.

[CHC reading]

(ii) $\approx$ He told me how much she had longed to go home.

[exclamative reading]

Thus whilst factivity is a property which exclamatives and CHCs hold in common with factive that-clauses, it is just one component of the meaning of the former two clause-types.

\section{The distribution of complementiser-how clauses}

Accounts differ in whether they emphasise the factivity shared by (factive) thatclauses and exclamatives, considering them as two different syntactic exponents of a single interpretive type 'fact' (Ginzburg \& Sag 2000: 64), or whether they rather focus on what is unique about the interpretation of these two kinds of FCC (Grimshaw 1979), analysing each as a distinct interpretive type (see Table 3). Both types of account make predictions as to what is expected for the distribution of $\mathrm{CHCs}$.

Table 3. The interpretive types of certain FCCs

\begin{tabular}{lll}
\hline & Grimshaw (1979) & Ginzburg \& Sag (2000) \\
\hline non-factive that-clause & proposition & proposition \\
factive that-clause & proposition & fact \\
exclamative & exclamation & fact \\
CHC & ??? & ??? \\
\hline
\end{tabular}

Given the interpretation CHCs receive, they seem best incorporated into Ginzburg \& Sag's (2000) system as 'facts', like factive that-clauses and exclamatives. Question complements can additionally be coerced into 'facts' by factive predicates (Ginzburg \& Sag 2000: 74), but as interrogative clauses are not pertinent to my current concerns, I do not explore this possibility here. Therefore if matrix 
predicates select for FCC complements on the basis of interpretive type, there are only two relevant options: A matrix predicate either permits 'fact' complements, or rejects 'fact' complements. Hence the three factive FCCs are predicted to show an identical distribution. This prediction is not met, as classes 3 and 4 of Table 4 make clear.

Table 4. Overview of the distribution of factive that-clauses, $\mathrm{CHCs}$ and exclamatives

\begin{tabular}{lllll}
\hline \multicolumn{1}{c}{ predicate classes } & factive that-clause & CHC & exclamative \\
\hline 1 & find out, see, forget & $\mathrm{y}$ & $\mathrm{y}$ & $\mathrm{y}$ \\
2 & believe, think, claim & $\mathrm{n}$ & $\mathrm{n}$ & $\mathrm{n}$ \\
3 & describe, detail, discuss & $\mathrm{n}$ & $\mathrm{y}$ & $\mathrm{y}$ \\
4 & sorry, happy, glad & $\mathrm{y}$ & $\mathrm{n}$ & $\mathrm{n}$ \\
\hline
\end{tabular}

Grimshaw (1979:323) already observed that not all predicates which select factive that-clauses also permit exclamative complements, and indeed, whilst there are many predicates under which factive that-clauses (a), exclamatives (b) and CHCs (c) are consistently accepted (13), or rejected (14) (classes 1 and 2 in Table 4), crucially there are also certain predicates which reject that-clause complements, but nevertheless allow exclamatives and CHCs (15), or conversely permit factive that-clauses, but not exclamatives or CHCs (16) (classes 3 and 4 in Table 4). Yet in a system where matrix predicates select complements on the basis of interpretive type, FCCs of the same interpretive type should not diverge in distribution.

(13) a. We found out/saw/forgot [that they couldn't return home].

b. We found out/saw/forgot [what a dreadful experience it was].

c. We found out/saw/forgot [how they couldn't return home].

(14) a. \#We believed/thought/claimed [that they couldn't return home]. ${ }^{8}$

b. ${ }^{\star}$ We believed/thought/claimed [what a dreadful experience it was].

c. ${ }^{\star}$ We believed/thought/claimed [how they couldn't return home].

(15) a. ${ }^{*}$ We described/detailed/discussed [that they couldn't return home].

b. We described/detailed/discussed [what a dreadful experience it was].

c. We described/detailed/discussed [how they couldn't return home].

(16) a. We are sorry/happy/glad [that they couldn't return home].

b. ${ }^{\star}$ We are sorry/happy/glad [what a dreadful experience it was].

c. ${ }^{\star}$ We are sorry/happy/glad [how they couldn't return home].

Grimshaw's (1979) account does not naturally extend to capture these data either. Given that she assigns that-clauses the type 'proposition', and exclamatives the type 'exclamation', there seems equal semantic justification for $\mathrm{CHCs}$ qualifying as their own distinct interpretive type. Yet if this were the case, the fact that CHCs and 
exclamatives have precisely the same distribution is surprising. It could only be captured by stipulating that exactly the same range of predicates select for both of these types of FCC. Whilst such a system could be implemented, it would inevitably involve a lot of redundancy.

The empirical patterns rather seem to suggest that $\mathrm{CHCs}$ and exclamatives must constitute one interpretive type, if FCCs are indeed selected on the basis of their interpretive type. Yet not only does this give no explanation for the fact that there are many contexts in which factive that-clauses do pattern alike with exclamatives and CHCs, it is also difficult to conceive of an interpretive characterisation which captures both CHCs and exclamatives to the exclusion of factive thatclauses. Regardless of the particular implementation chosen, accounts which tie the distribution of FCCs directly to their interpretive type cannot parsimoniously capture the broader range of distributional data presented here. What is needed is a more fundamental rethinking of the factors which determine the distribution of FCCs.

\section{Accounting for the distribution of complementiser-how clauses}

$\mathrm{CHCs}$ and exclamatives are factive, but they are not the only factive complement clauses - there is also a 'factive' flavour of that-clause. Similarly, whilst CHCs and exclamatives are both introduced by wh-expressions, this characterisation does not differentiate them from embedded interrogatives. However, what does distinguish CHCs and exclamatives from all other FCCs under consideration is the confluence of these two properties: CHCs and exclamatives are unique in being both factive, and introduced by $w h$-expressions.

Table 5. Characterisation of the distributionally-relevant properties of English FCCs

\begin{tabular}{lll}
\hline Type of complement clause & {$[+/-w h]$} & {$[+/-$ factive $]$} \\
\hline exclamative & $+w h$ & + factive \\
CHC & $+w h$ & + factive \\
factive that-clause & $-w h$ & + factive \\
interrogative & $+w h$ & - factive \\
non-factive that-clause & $-w h$ & -factive \\
\hline
\end{tabular}

I therefore propose that $\mathrm{CHCs}$ and embedded exclamatives share a specification for the syntactically encoded properties $[+w h,+$ factive]. This is part of the broader system that I envisage, summarised in Table 5 , in which all FCCs can be characterised in terms of the binary features [+/-wh, +/- factive]. Thus factive that-clauses share with exclamatives and CHCs the property of being [ + factive], but differ in 
being [-wh]. For the sake of completeness I add interrogative clauses, which share the $[+w h]$ specification of CHCs and exclamatives but not their factivity, and nonfactive that-clauses, which are both $[-w h]$ and [-factive $].{ }^{9}$ To be clear, my claim is not that such feature specifications are sufficient to characterise the syntax or interpretation of the FCCs in question. They are intended as an inventory of all and only the features which matrix predicates make reference to in selecting for FCCs.

Just as in Ginzburg \& Sag's (2000) account, the system I propose allows the factivity common to $\mathrm{CHCs}$, exclamatives and factive that-clauses to be captured, and attributes it a key role in determining the distribution of these FCCs. It departs from Ginzburg \& Sag (2000), however, firstly in additionally differentiating the former two types of FCC from the latter in terms of the $[+/-w h]$ distinction, and secondly in encoding both this and factivity in the syntax of FCCs. ${ }^{10}$ There is independent support for both these innovations. Whilst I cannot hope to do justice to the vast literature, I cite some key works.

Numerous accounts posit $w h$ as a syntactically relevant feature for the selection of complement clauses. Watanabe (1993:526) explicitly claims that "[ $t$ ]here are only two types of clauses to be selected by a verb, namely wh-clauses and nonwh-clauses", although the full range of facts cannot be captured with this distinction alone. Notably, Watanabe (1993:529) has recourse to a "factive operator... selected by the higher verb". Treating $w h$ as a formal syntactic feature is not uncontentious, however. Other accounts (e.g. Šimík 2008) have rather sought to find a common semantic component to all uses of $w h$. However, with complementiser how added into the picture, it seems hard to maintain such a position.

The view that the semantic property of factivity is syntactically encoded in that-clause complements has been widespread since Kiparsky \& Kiparsky (1971), and the idea that the (non-)factivity of an FCC influences the range of matrix predicates under which it can occur is already present in their work. A syntactic encoding of factivity in other factive clauses has also been proposed (cf. Zanuttini \& Portner (2003) for exclamatives, Legate (2010) for CHCs). Thus the novelty of my account is not in positing wh or factivity as syntactically-encoded components of FCCs, nor in suggesting that these are relevant for selection, but rather in claiming that both of these in combination determine the distribution of all FCCs in English.

Having motivated the characterisation of English FCCs presented in Table 5, I turn to show how this captures the distributional patterns presented in Table 4. Table 6 characterises the predicate classes identified in terms of the requirements they place on their FCC complements. ${ }^{11}$ Classes 1 and 3 select for $[+w h,+$ factive] complements, thus allowing $\mathrm{CHCs}$ and exclamatives. The former also selects for $[-w h,+$ factive $]$ complements, additionally allowing factive that-clauses. Classes 2 and 4 do not permit $[+w h,+$ factive $]$ complements, thus CHCs and exclamatives 
are excluded. I do not claim to offer a deep explanation as to why predicates differ in the selectional requirements they place on their complements. Rather, I provide a novel and more accurate characterisation of the distributional patterns observed than has been offered to date. As my goal is to show the general empirical advantages such an approach offers over the traditional view of selection for interpretive type, I do not take a stance here on the precise encoding of the [+/-wh, +/-factive] specification of FCCs, nor on the implementation of the relation between matrix predicate and complement clause, although both of these issues deserve attention in future work.

Table 6. Selectional requirements of English FCC-taking predicates

\begin{tabular}{lll}
\hline & predicate classes & properties of their FCCs \\
\hline 1 & find out, see, forget & {$[+/-w h,+$ factive $]$} \\
2 & believe, think, claim & {$[-w h,-$ factive $]$} \\
3 & describe, detail, discuss & {$[+w h,+$ factive $]$} \\
4 & sorry, happy, glad & {$[-w h,+$ factive $]$} \\
\hline
\end{tabular}

\section{Consequences for interpretive type}

Thus far I have argued that FCC-selection does not make direct reference to the interpretive type of a clause. This follows automatically if, as proposed by Zanuttini \& Portner (2003:39) on grounds entirely independent of selection, clauses do not in fact involve an interpretive type, in the sense of a semantically (or syntactically) encoded primitive. Rather, interpretive type is determined compositionally, on the basis of particular syntactic components. For instance, in order for a clause to receive the semantic denotation of an exclamation, both a factive operator and a wh-operator-variable configuration must be present in the syntax (Zanuttini \& Portner (2003: 40). ${ }^{12}$ Noting the striking similarity to the $[+w h,+$ factive $]$ selectionally-relevant specification which I independently assigned to exclamatives, I tentatively hypothesise that the features of a FCC which are relevant for its selection by a matrix predicate are related to (a sub-set of) the properties which contribute to determining the interpretation of the FCC. In this spirit, it seems plausible that $\mathrm{CHC}$ interpretation similarly relies upon the presence of a factive operator and a $w h$-expression, which contribute the same selectionally-relevant $[+w h,+$ factive $]$ syntactic specification as in exclamatives. The interpretive and syntactic differences CHCs show to exclamatives arise from the fact that the $w h$-expression in the former is a complementiser, in the latter an operator. This points to the conclusion that the distribution of FCCs is not entirely divorced from their interpretation, 
although the connection is much more indirect than in the accounts discussed to date. This requires future corroboration on the basis of a broader range of complement clauses. ${ }^{13}$

\section{Conclusions}

In this paper I have presented new empirical patterns in the distribution of English FCCs which emerge when the data set is expanded to take CHCs into consideration. The common distribution of CHCs and exclamatives throws into question the standard view of matrix predicates selecting for FCC complements on the basis of interpretive type. I argued for an alternative approach, whereby the distribution of FCCs is rather determined by their syntactic specification in terms of the features [+/-wh, +/-factive]. A detailed investigation of how embedded interrogative clauses fit into this system is a topic for future research.

\section{Notes}

* I am grateful to my supervisor, Liliane Haegeman, and to my fellow GIST team-members for their input. Thanks also to the audience of TIN-dag 2013, and to Hans Broekhuis in particular for his encouragement. This work has benefitted from the comments of two anonymous reviewers. All errors and inaccuracies are my own. This research was funded by the FWO [Grant 2009-Odysseus-Haegeman-G091409].

1. Grimshaw (1979:280) in fact designates these as "semantic types". I make use of the term 'interpretive type' to avoid confusion with the semantic types of type theory.

2. Grimshaw (1979) posits that predicates also categorically select for CP or DP complements. My focus here is not on the issue of why only certain predicates permit CP complements, but rather on the possible realisations of $\mathrm{CP}$ complements for those predicates which do permit them.

3. Ask can in fact take that-clause complements, but only in the subjunctive mood. Subjunctive clauses are not discussed by Grimshaw (1979) and are similarly beyond the scope of this paper.

4. This claim holds for think in a declarative matrix clause in the simple present or past tense, where think means 'to hold the opinion'. As a reviewer notes, exclamative complements to imperative think (with a meaning closer to 'consider') are possible (i). However, as CHCs are similarly possible in this context (ii), the common distribution observed in Table 4 is maintained. A similar point can be made for believe vs. can't believe.

(i) Just think [what a close call that was].

(ii) Just think [how he never once visited]. 
5. As a reviewer correctly observes, under certain predicates, such as tell, lie about, go on about, the factivity of CHCs appears to be suspended (i). Crucially, however, so is the factivity of an embedded exclamative (ii), as Abels (2010) observes. He argues that this behaviour is typical of presupposition-carrying expressions, and thus provides support rather than counter-evidence for their factivity.

(i) He lied about [how Mary was never late]. $\nRightarrow$ Mary was never late

(ii) He lied about [what a great cook he was]. $\nRightarrow$ he was a great cook

6. The presence of negation inside a CHC reduces the likelihood of ambiguity with other wh complement clauses, as it usually has the effect of excluding question and exclamation interpretation. For this reason, the $\mathrm{CHC}$ examples I construct all involve negation.

7. For ease of exposition, in subsequent examples I use clauses introduced by the unambiguously exclamative $w$-expression what $a$.

8. The string in (14a) is grammatical, but the that-clause complement is non-factive.

9. In fact, given the work of McCloskey (2006), a distinction may be needed between two kinds of interrogative complement clause, the 'true interrogative' complements to ask and wonder, which would have the [+wh, -factive] specification, and the 'resolutive' complements to tell and find out, which would share with CHCs and exclamatives both the $[+w h,+$ factive $]$ specification, and their distribution.

10. Ginzburg \& Sag (2000:70 f.n. 19) do in fact discuss the idea that the syntactic property of $[+/-w h]$ may also be of relevance in determining the distribution of FCCs, although ultimately deem this "superfluous" to the semantic distinctions they make. Yet without such a distinction, their account predicts a common distribution for factive that-clauses and exclamatives.

11. The classes of matrix predicates identified here are by no means exhaustive. For instance, predicates such as ask, wonder realise the other basic logical possibility, which is a requirement for predicates which are $[+w h$, -factive]. The empirical generalisations made to date hold even when the data set is expanded.

12. Zanuttini \& Portner's (2003) proposal is for matrix exclamatives, but I see no reason not to apply this in the embedded domain.

13. Interrogatives, in Zanuttini \& Portner's (2003) system, similarly involve a wh operatorvariable relation, but no factive operator. This is compatible with the [+wh,-factive] selectional specification which I assign to them.

\section{References}

Abels, Klaus. 2010. Factivity in exclamatives is a presupposition. Studia Linguistica 64(1). 141-157.

Defrancq, Bart. 2009. Comment narratif. Travaux de Linguistique 58(1). 89-106.

Ginzburg, Jonathan \& Ivan Sag. 2000. Interrogative investigations. Stanford: CSLI Publications.

Grimshaw, Jane. 1979. Complement selection and the lexicon. Linguistic Inquiry 10(2). 279-326. 
Karttunen, Lauri. 1973. Presuppositions of compound sentences. Linguistic Inquiry 4(2). 169-193.

Kiparsky, Paul \& Carol Kiparsky. 1971. Fact. In Manfred Bierwisch \& Karl Erich Heidolph (eds.), Progress in Linguistics, 143-173. The Hague: Mouton.

Legate, Julie Anne. 2010. On how how is used instead of that. Natural Language and Linguistic Theory 28. 121-134.

McCloskey, Jim. 2006. Questions and questioning in a local English. In Raffaela Zanuttini, Héctor Campos, Elena Herburger \& Paul H. Portner (eds.), Crosslinguistic research in syntax and semantics: Negation, tense and clausal architecture, 87-126. Georgetown: Georgetown University Press.

Nye, Rachel. 2012. The categorial status of Dutch and English declarative hoe-/how-complement clauses. In Marije van Hattum, Jonathan Morris \& Dorothea Hoffman (eds.), Salford working papers in Linguistics and Applied Linguistics 2, 28-47. Salford: University of Salford.

Rizzi, Luigi. 1997. The fine structure of the left periphery. In Liliane Haegeman (ed.), Elements of grammar, 281-337. Dordrecht: Kluwer.

Shanon, Benny. 1976. On the two kinds of presuppositions in natural language. Foundations of Language 14. 247-249.

Šimík, Radek. 2008. The source of wh-morphology in questions and relative clauses. In Sylvia Blaho, Camelia Constantinescu \& Erik Schoorlemmer (eds.), Proceedings of the Conference of the Student Organisation of Linguistics in Europe (ConSOLE) XV, 273-294. Published online. http://www.hum2.leidenuniv.nl/pdf/lucl/sole/console15/console15-simik.pdf. (4 January, 2013)

Warner, Anthony. 1982. Complementation in Middle English and the methodology of historical syntax: A study of the Wyclifite sermons. London: Croom Helm.

Watanabe, Akira. 1993. Larsonian CP recursion, factive complements, and selection. Proceedings of the 23rd Annual Meeting of the North East Linguistic Society (NELS), 523-537. Amherst, Massachusetts: GLSA.

Zanuttini, Rafaella \& Paul Portner. 2003. Exclamative clauses: At the syntax-semantics interface. Language 79. 39-81.

\section{Author's address}

Rachel Nye

Ghent University

Blandijnberg 2

Ghent 9000, Belgium

rachel.nye@gmail.com 